\title{
FILOSOFIA E LITERATURA \\ O problema moral no «Grande Sertão: Veredas»
}

\author{
ALVARO MARTINS ANDRADE
}

\begin{abstract}
"Mas liberdade - aposto - ainda é só alegria de um pobre caminhozinho, no dentro do ferro de grandes prisões. Tem uma verdade que se carece de aprender, do encoberto, e que ninguém não ensina: o bêco para a liberdade se fazer." (GSV, 290) (1).
\end{abstract}

"A liberdade é assim, movimentação." (GSV, 303) .

"ROSA:

Sim, fui médico, rebelde, soldado. Foram etapas importantes da minha vida, e, em rigor, a seqüência representa um paradoxo. Como médico, conheci o valor místico do sofrimento; como rebelde, o valor da consciência; como soldado, o valor da proximidade da morte...

\section{LORENZ:} valores?

Deve-se entender isso como uma escala de

ROSA:

Exato, é uma escala de valores.

\section{LORENZ:}

E não são esses três conhecimentos, no fundo, a espinha dorsal do romance "Grande Sertão"?

(1) Toda's as citações do Grande Sertão: Veredas são feitas sobre a 2.a edição - que é a definitiva. 
ROSA:

São, mas somam-se ainda outros, sobre os quais nós temos ainda de falar também." (2)

"Gosto de achar que tudo evolui e avança necessàriamente bem."

Guimarães Rosa ${ }^{(3)}$

"O inconsciente é capaz, por momentos, de manifestar mais inteligência e finalidade do que não o é a introspecção consciente."

Jung (4)

A exemplo de toda a travesia do Riobaldo - ou de toda filosofia - a gênese do pensamento moral de Guimarães Rosa se dá segundo um processo que comporta etapas prévias e necessárias. Com efeito, encontra-se no Grande Sertão: Veredas se não uma sistemática "filosofia das ciências", pelo menos um narrador que reflete sobre o conhecimento do seu mundo e do teu tempo, a ponto de já poder "formular" a "hipótese" (ou "tese"?):

"Ao que, este mundo é muito misturado..."

(GSV, 210, grifo nosso)

Embora o problema de uma filosofia das ciências no Grande Sertão: Veredas não esteja compreendido na presente análise, ainda assim é necessário assinalar - para os efeito da análise posterior - que o narrador tem uma síntese coerente de conhecimentos sobre o universo e o homem. Mesmo sem se poder falar ainda e rigorosamente de filosofia, trata-se de uma indagação preliminar que estabelece efetivamente certos referenciais fixos neste "mundo movente" para usar a feliz expressão de José Carlos Garbuglio ${ }^{(5)}$.

Encontramos em seguida uma metafísica - no sentido

(2) in LORENZ, Günter - Literatura Deve Ser Vida. Um Diálogo de Gïnter W. Lorenz com João Guimarães Rosa. Trad. Jehovanira Füchtner e Chrysóstomo de Sousa, do livro Dialog mit Lateinamerika. Panorama einer Literatur Zukunft - Tübingen, Horst Erdman, 1970. Publ. in Exposição do Novio Livro Alemão - 1971, org. "Austellungs-und MesseCrmbH Börsenvereins des Buchhandels" em col. Institutos Culturais Brasileiro-Alemães. Págs. 272-273.

(3) Carta a Dora Ferreira da Silva, de 19.2.1958, in Cavalo Azul, S. Paulo, $3: 33$, s.d.

(4) JUNG, Carl Gustav - Psychologie et Religion - Trad. Marthe Bernson e Gilbert Cahen, Paris, Buchet/Chastel, 1958, p. 80.

(5) O Mundo Morente de Guimarães Rosa. São Paulo, Ed. Ática, 1972. 
de uma complementação, seguramente sempre hipotética, do fragmentário quadro de conhecimentos sobre o mundo e o homem. "Digo: o real não está na saída nem na chegada: ele se dispõe para a gente é no meio da travessia." (GSV, 62-63) . Por isso, seguramente, "o real roda e põe adiante." (GSV, 133) Sem pretender ser superior à "ciência" representada pelo seu interlocutor silencioso, a "metafísica" do narrador ou do compadre meu Quelemém ainda assim visa sempre preencher de maneira "razoável" as persistentes lacunas do conhecimento "científico":

"A razão normal de coisa nenhuma não é verdadeira, não maneja." (GSV, 334),

diz o narrador, talvez melhor esclarecendo suas curiosas referência e descrição do compadre Quelemém, o qual

"quer saber tudo diverso: quer não é o caso inteirado em si, mas a sobre-coisa, a outra coisa." (GSV, 189, grifos nossos)

Da mesma forma que para o seu autor ${ }^{(6)}$, também para o narrador o ético e o metafísico são inextrincavelmente interdependentes. A partir dos dois conceitos que este sábio ex-jagunço mais elabora - destino e liberdade - ocuparnos-emos agora do ético e do metafísico, com vistas à determinação do conceito que (embora não referido nominalmente pelo narrador) a nosso ver informa toda a sua ação e pensamento: o finalismo inerente à existência humana, o quantum de necessidade que define o sentido comum, invariável e universal dos mitos do herói.

A idéia de um finalismo inerente à substância já se encontra presente no sistema aristotélico: na passagem da potência para o ato, da forma para a matéria, quando o dynamós realiza as melhores potencialidades, já é com a finalidade de realizar "o melhor dos mundos possíveis." $\mathrm{Ne}-$ gada pelo Pascal cartesiano ("As flôres e os passarinhos não demonstram"), esta orientação ou finalidade interior ao dynamós e à substância, realizando-se continuamente pela transformação (que desta forma supõe o tempo) implicará assim na irreversibilidade, com todas as suas conseqüências que, no caso do narrador, serão de ordem sobretudo ética

(6) Cf. Literatura Deve Ser Vida - entrevista a Günter Lorenz, op. cit., passim. 
porque também psicológicas. "A partir de um certo ponto, não há mais retôrno. Esse é o ponto que se precisa atingir" - já o sabia o Kafka das Considerações sobre o pecado, a dor, a esperança e o verdadeiro caminho. Nosso narrador vai mais longe: associa e coloca este "ponto" crítico ("ponto de marca") no interior do finalismo ("Tudo tinha me torcido para um rumo só") - e portanto inerente a este, verdadeira finalidade no interior da necessidade:

"Tem um ponto de marca, que dele não se pode mais voltar para trás. Tudo tinha me torcido para um rumo só, minha coragem regulada sómente para diante, sómente para diante." (GSV 203, grifos nossos) .

Acreditamos ter deixado suficientemente claro, em outras análises dedicadas especificamente ao problema (7), que o "rumo só" para o qual está "minha coragem regulada" é o rumo do inconsciente, o do mergulho nas imagens primordiais do mito pessoal. "Tendo atravessado o Rubicão, seria impossível voltar atrás", diz Jung valendo-se também das (no caso) indispensáveis metáforas. (8)

Reconhecemos que a insistência com que o narrador direta ou indiretamente - refere o destino, autorizaria pensar em uma concepção de homem de tipo determinista ou fatalista. Observe-se, contudo, que não só o próprio conceito quanto suas variantes são sempre utilizadas de maneira ambígua, de maneira tal que se tem desde sua categórica afirmação até sua radical negação, passando por outros usos metafóricos e poéticos que permitirão determinar seu verdadeiro valor significativo. Associados a outras "falas", tais usos possibilitam determinar seu sentido original. No primeiro caso (acepção ingênua e determinista), tem-se o narrador se referindo à adivinha Ana Duzuza, mãe de Nhorinhá:

"No momento, foi que eu caí em mim, que podia ter perguntado à Ana Duzuza alguma passagem de minha sina por vir. (...) E se a Duzuza adivinhasse mesmo, conhecesse por detrás o pano do destino?” (GSV, 35, grifos nossos)

(7) "O Sertão é o inconscicnte", "O sonho e o mito: universo e linguagem", "Matéria e matéria vertente no Grande Sertão" - in Revista de Letras, Vol. 16, 1974.

(8) JUNG, C. G. - Psychologie et Alchimie, Trad. Dr. Roland Cahen e Henry Pernet, Paris, Buchet/Chastel, 1970, p. 161. 
Com a mesma acepção (embora sem referí-lo), reaparece na estória de Davidão e Faustino, na qual, como após o pacto entre ambos nenhum dos dois morre, o narrador diz que "Para nenhum deles tinha chegado a hora-e-dia." (GSV, 81, grifos nossos) $\mathrm{Ou}$, ainda, referindo-se a Fancho-Bode e Fulorêncio, que "Morreram, porque era seu dia, deles, de boa questão." (GSV, 154, grifo nosso) Entretanto, descrevendo os momentos que precederam ao pacto, o narrador já fala d'“o alto destino possivel da gente" (GSV, 381, grifo nosso), introduzindo assim a primeira "variação" que, por si mesma, negaria a noção estrita de um "destino" enquanto determinismo, pre-determinismo ou fatalismo. A menos que se conceba a paradoxal duplicidade do destino - um "alto" e outro "baixo". O "possível", aqui, já abre necessariamente para uma concepção de liberdade que, se não nega a necessidade do determinismo estrito, a relativiza em finalismo. Ou, se é possível dizê-lo - a liberdade no interior da necessidade se traduz em permanente atualidade livre:

"E o que era para ser. O que é pra ser - são as palavras." (GSV, 47, grifos nossos)

Esta "relativização" do destino é nitidamente sugerida pelo narrador ao se perguntar se

"Deveras se vê que o viver da gente não é tão cerzidinho assim?" (GSV, 106, grifos nossos),

pois na realidade ele também conhece e admite o que chama de "acaso" e sua importância:

"Ao que, digo ao senhor, pergunto: em sua vida é assim? Na minha, agora é que vejo, as coisas importantes, todas, em caso curto de acaso foi que se conseguiram - pelo pulo fino de sem ver se dar - a sorte momenteira, por cabelo por um fio, um clim de clina de cavalo. Ah, e se não fosse, cada acaso não tivesse sido, qual é então que teria sido o meu destino seguinte? Coisa vã, que não conforma respostas. As vezes essa idéia me põe susto." (GSV, 120-121, grifos nossos)

Se o determinismo estrito ("destino") é assim limitado e relativizado pelo narrador, a tal ponto este já se represeenta claramente sua concepção d'“essa idéia", que chega ao extremo cuidado de relativizar também o oposto - isto é, a "liberdade de escolha" - antecipando de quase quatrocen- 
tas páginas o conceito-chave de sua concepção da existência humana ("Cumpro." - GSV, 571):

"Quem que diz que na vida tudo se escolhe? O que castiga, cumpre também." (GSV, 205, grifos nossos)

O problema que se coloca, portanto, seja para o narrador, seja para nós, é o seguinte: o destino do homem é problema de Deus, ou do próprio homem? Ao nível da narrativa dos "fatos", o artifício utilizado para elaborar o tema será o mesmo utilizado pelo Goethe do Fausto: a aposta, o pacto (Fausto será perdido? Fausto se perderá?). Ora, em relação ao "Deus" do narrador, se é verdade que ele "quer" alguma coisa em relação ao homem, é preciso reconhecer que não sòmente se trata de um objetivo bastante simples e "saudável" (a "alegria"), como também será necessário reconhecer que este mesmo "Deus" "respeita" a liberdade do homem ("na horinha em que se quer"):

"O que Deus quer é ver a gente aprendendo a ser capaz de ficar alegre a mais, no meio da alegria, e inda mais alegre ainda no meio da tristeza! Só assim de repente, na horinha em que se quer, de propósito - por coragem." (GSV, 301, grifos nossos)

Além do já verifcado em relação a esse Deus do narrador como categoria antropológica e imagem do centro ou $\mathrm{Si}{ }^{(9)} \mathrm{seu}$ "parentesco" com o diabo, esta humanidade liberal de um Deus que assim respeita a liberdade humana verifica-se ainda pela conseqüente solidariedade e responsabilidade que decorreria do próprio "pacto":

"Se vendo minha alma, estou vendendo também a dos outros." (GSV, 294, grifo nosso)

Mas não nos iludamos, não se trata de um existencialista a repetir os lugares-comuns sartrianos. Já vimos que, na realidade, enquanto o narrador "brinca" com diferentes jargões filosóficos ou pseudo-filosóficos, simultaneamente "dialetiza" entre os sistemas originários destas linguagens, em busca de sua síntese pessoal. Observe-se que, de tomar ou

(9) Cf. ANDRADE, Ålvaro Martins - "Matéria e Matéria Vertente no Grande Sertão", Revista de Letras da Faculdade de Filosofia, Ciências e Letras de Assis, Vol. 16, 1974. 
interpretar isoladamente algumas falas "sentenciosas" do narrador, sem previamente estabelecer seu contexto subjetivo e o global de seu universo, poder-se-ia em conseqüência "definir" sucessivamente seu "pensamento" não apenas como "existencialista" (10), mas também "spinosano", "kantiano" e outros mais.

Com efeito, descrevendo a entrada no sertão de Minas, na perseguição final ao Hermógenes, ao mesmo tempo que reafirma a já apontada irreversibilidade da específica "travessia" que está realizando (a do inconsciente para o consciência), o narrador "se revelaria" também como um "spinosano":

'Dali de lá, eu podia voltar, não podia? Ou será que não podia, não? Bambas asas, me não sei. Bambas asas... Sei ou o senhor sabe? Lei é asada é para as estrêlas. Quem sabe, tudo o que já está escrito tem constante reforma - mas que a gente não sabe em que rumo está - em bem ou mal, todo-o-tempo reformando?” (GSV, 510, grifos nossos)

Se é verdade que " $a$ ilusão da liberdade vem da consciência de nossa ação e da ignorância das causas que nos fazem agir" (11), o narrador seria realmente um "spinosano" ("tudo... está escrito... a gente não sabe..."); entretanto observe-se: "tudo o que já está escrito tem constante refor$m a$ ": a liberdade não é uma "ilusão" nem o narrador um "spinosano".

Tem sido esse mesmo tipo de análise (sem levar em conta o contexto subjetivo e global de um narrador que "brinca" com as linguagens dos "sistemas" filosóficos) o que, a nosso ver, tem ocasionado, na crítica rosiana até aqui publicada, a aproximação mais freqüente das "idéias filosóficas" do narrador com as assim chamadas "vertentes existencialistas". E, realmente, se adotado o critério fácil da simples justaposição, pode-se de fato "provar" por tal meio

(10) Como já tem efetivamente ocorrido na crítica; cf., p. ex., CARDOSO, Wilton - "A estrutura da Composição em Guimarães Rosa", Ciclo de Conferências sôbre Guimarães Rosa, Universidade Federal de Minas Gerais - Centro de Estudos Mineiros - Div. autores, Belo Horizonte, 1966 , p. 47.

(11) SPINOSA, Ethique, trad. Appuhn, Paris, Garnier, 1958, II, prop. XXXV; escólio.. Grifos nossos. 
que o narrador é um "sartriano". Se não, vejamos: discutindo o problema da liberdade em Descartes, Sartre observa que "ele compreendeu, melhor que ninguém, que a menor démarche do pensamento engaja todo o pensamento, um pensamento autônomo que se põe, em cada um de seus atos, em sua independência plena e absoluta." (12) Se assim é e com a mesma facilidade de critério das simples aproximações - nosso narrador seria "sartriano" quando diz que

"Ações? O que eu vi, sempre, é que toda ação principia mesmo é por uma palavra pensada." (GSV, 170, grifos nossos),

hipótese que imediatamente se "verificaria" pela afirmação de que "A liberdade é assim, movimentação." (GSV, 303, grifos nossos) .

Entretanto, não esqueçamos que para o narrador, a liberdade é essencialmente uma libertação: libertação das trevas do "não-saber" (GSV, 96, 97, 133, 272, 294), do seu "sertão" (GSV, 149, 270, 271, 274, 334, 354, 409, 432, 466, 486-487, 490, $491,501,510,540,560)$, enfim, libertação em relação ao seu inconsciente. "Sujeição e possessão são sinônimos. Esta a razão pela qual há sempre algo na alma que toma a dianteira, limita ou põe em xeque a liberdade moral"(13). E não esqueçamos que, se Diadorim é o grande "personagem" deste inconsciente, na fase inicial e caótica do herói "As vontades de minha pessoa estavam entregues a Diadorim." (GSV, 37) Não obstante, "enquanto ser natural, simpelsmente criado ou emerso de pre-condições inconscientes, o homem não tem nenhuma liberdade e a consciência não tem nenhuma 'razão de ser'. O julgamento psicológico deve ter em conta que, em virtude do fato de que a despeito de toda sua intrincação causal, o homem possui um sentimento de liberdade que se confunde com a autonomia da consciência. Embora todas as coisas, tomadas uma a uma, provem ao Eu que ele é dependente e condicionado, não se pode entretanto persuadí-lo de sua escravidão." (14) Convenhamos que, tomada passo a passo a evolução do jagunço Riobaldo ao Chefe Urutú Branco e, finalmente, ao narrador-enquanto-narrador ("hoje", "agora"), não se confundem a falta de "razão de ser"

(12) SARTRE, I. P. - Situations I, Paris, Gallimard, 1947, p. 314. Grifos nossos.

(13) JUNG, Psychologie et Religion, op. cit., p. 172. Grifos nossos.

(14) JUNG, L'Ame et la Vie, Paris, Buchet/Chastel, 1963, p. 281. 
inicial do primeiro (GSV, 11, 272 etc.), o "sentimento de liberdade que se confunde com a autonomia da consciência" do segundo (GSV, 437, 527 etc.) e a liberdade-libertação de que goza o terceiro e último: "Agora, paz." (GSV, 432) Pensada assim, como árdua e penosa libertação do "dentro do ferro de grandes prisões" do inconsciente, comprende-se então que também a "verdade" da liberdade tenha de ser aprendida nesta solitária conquista a partir do "encoberto":

"Vento que vem de toda parte. Dando no meu corpo, aquele ar me falou em grito de liberdade. Mas liberdade - aposto - ainda é só alegria de um pobre caminhozinho, no dentro do ferro de grandes prisões. Tem uma verdade que se carece de aprender, do encoberto, e que ninguém não ensina: o bêco para a liberdade se fazer." (GSV, 290, grifos nossos)

Avêssas a todo o "racional" e "intelectual", a ética e mesmo a metafísica do narrador e seu autor serão sempre fundadas no vivido, numa concepção geral do universo e do homem simultâneamente "experimentada" e verbalizada ao longo da narrativa. Procuremos assim, agora, determinar a forma e as conseqüências práticas que - para a ação - tem esta concepção ético-metafísica do homem e do universo.

O que estamos chamando de "metafísica", no Grande Sertão: Veredas é o conjunto de proposições "sentenciosas" e "textos teóricos" (15) que - transcendendo as aparentes "contradições" e "ambigüidades" - apresenta verdadeira homogeneidade entre si, completando assim as poucas certezas "racionais" do narrador e lhe permitindo resolver os problemas e desafios que lhe colocam sua existência e o mundo: o que é o sertão, o que é viver. Observe-se que as progressivas falas e respostas que definem especialmente a "metafísica" do narrador, também aí se dão segundo as possibili-

(15) A título de ilustração da natureza especialmente "teórica" de certas falas que - por este motivo - chamamos "textos teóricos", confronte-se, entre outros: pág. 39 (projeção, amor, inconsciente, função da linguagcm, homem interior e exterior); pág. 59 (Deus, vida, multiplicidade, clôr, nascimento-morte, inferno-diabo, Céu-fím); pág. 81 ("antes" e "loje", Chefiar, condição humana-encantamento, projeção); pág. 90 (Diadorim, vingança, diabo, "caminho certo", viver); pág. 270 (natureza mítica de Zé Bebelo, julgamento, centro, Joca Ramiro e Zé Pebelo); pág. 275 (natureza de Diadorim); págs. 292 e sgs. (dos mais importantes, síntese contendo "chaves" para quase todos os temas codificados); pág. 45.5-6 (diabo, pacto:negação); pág. 456 (processo, ética). 
dades de toda e qualquer metafísica. Isto é, todas as suas proposições que configuram um "sistema" se conformam segundo a adoção de uma crença radical, prévia e organizadora - mais de Guimarães Rosa que de Riobaldo - e que funciona como postulado fundante da metafísica em questão. Ora, tais possibilidades geradoras das metafísicas - sem pre referidas à "Ordem" ou à idéia de uma ordem - dão-se invariavelmente na raíz de toda e qualquer metafísica sob uma das três alternativas: há uma Ordem no universo; não existe Ordem alguma no universo; ou: uma ordem se ela. bora progressivamente. A adoção da terceira destas três alternativas encontra-se na raíz de toda a reflexão moral do narrador: uma ordem, um mundo e um homem in fieri, fazendo-se, em processo.

Muitas vezes o narrador faz pensar que Guimarães Rosa teria platonicamente optado pela afirmação de uma Ordem. Mas com o simples fato de fazer pensar o narrador, Guimarães Rosa revela estar muito mais próximo da terceira alternativa: toda Ordem é construção e elaboração progressiva: "Gosto de achar que tudo evolui e avança necessàriamente bem." (16) A própria adoção desta alternativa já é de certa forma uma "inclinação" inicial, absolutamente indemonstrável e provavelmente de natureza afetiva, semelhante, talvez, à que faz com que alguns de nós gostemos mais de Riobaldo, outros de Diadorim. Afinal, "A gente sabe mais de um homem, é o que ele esconde." (GSV, 319)

É esta inclinação ou opção pela Ordem in fieri, pelo movimento, transformação orientada e pela metamorfose do processo que, a nosso ver, constitui a verdadeira opção de Riobaldo-Rosa. Desta forma resulta ainda um tanto arbitrário quando dizemos que o pensamento moral de Riobaldo é o resultado ou conseqüência de uma elaboração metafísica anterior; na realidade, no caso deste narrador porta-voz de seu autor, o ético está na origem do "metafísico", ambos inextrincavelmente ligados ao psicológico. Neste sentido se pode dizer indiferentemente que o Grande Sertão: Veredas está construído de trás para diante ou de diante para trás: quando, encerrando sua "estória", o narrador diz que

"No que narrei, o senhor talvez até ache mais do que eu, a minha verdade" (GSV, 564, grifo nosso)

(16) Guimarães Rosa, Carta a Dora Ferreira da Silva, 19.2.1958, Cavalo Azul 11. ${ }^{0}$ 3, op. cit., p. 33. Grifos nosos. 
é porque efetivamente ele já tem essa "verdade", sabe que só é possível construir uma "metafísica" coerente a partir não de uma "razão normal de coisa nenhuma" - que "não é verdadeira, não maneja" (GSV, 334), mas sim a partir da "Verdade maior", essa "que a vida me ensinou." (GSV, 24, grifsos nossos). Mais precisamente ainda, a ética do narrador se constitui precisamente na elaboração desta intuição afetiva e anterior a qualquer construção lógico-filosófica, elaboração que assim se fazendo no modo da ingenuidade fenomenológica, ao nível da expressão se dará na forma da ambigüidade. Em última instância, o que o narrador procura (e procura definir) é o objeto mesmo de toda a filosofia - o sentido ou não-sentido do universo, desse viver que "nem não é muito perigoso" (GSV, 35), o sentido de sua própria existência. É esta "intuição", "visão" ou modo de sentir o mundo que, se ao nivel do poético resulta na criação visionária, ao nível do ético já é de natureza "moral": desenvolvendo-se, realizando-se e objetivando-se no processo, toma forma e consciência de si mesma através da reflexão que prova, organizando-se finalmente em discurso e pensamento moral. Resultados de um engajamento do coração e do sentimento, ética e metafísica rosianas se dão assim em um só movimento; sòmente para efeito de análise se pode considerá-las separadamente.

\section{ENGAJAMENTO DO SENTIMENTO E ENGAJAMENTO DA VONTADE}

"Eu queria minha vida própria, por meu querer governada." (GSV, 335)

"Quem me entende? O que eu queira. Os fatos passados obedecem à gente; os em vir, também. Só o poder do presente é que é furiável? Não. Êsse obedece igual - e é o que é. Isto, já aprendi." (GSV, 324-325)

Graças a um artigo de Karl Krolow tem-se por definitivamente assentado que toda a obra de Guimarães Rosa e por consequência também seu pensamento - se constituem em um engajamento do coração, ou um engajamento do sentimento. (17) O próprio autor, aliás, jamais negou ou objetou qualquer coisa a respeito. Entretanto, por suas con-

(17) Krolow, Karl - "Brasilianisches Epos - João Guimarães Rosa: Corps de Ballet”, Sïddeutsche Zeitung, Francforte/s/Meno, 8.12.1966. 
sequências e significação para a determinação do que chamamos um pensamento brasileiro, urge retomar esta afirmação e verificar em que medida a mesma é verdadeira - mas não toda a verdade. Isto só é possível de ser feito a partir sobretudo do próprio texto.

Tomado o Grande Sertão: Veredas como dimensão maior da realização do mito pessoal do homem e artista João Guimarães Rosa, embora sua vida pessoal e seus depoimentos devam contar, são ainda seus textos a sua maior objetivação.

Com efeito, a maior parte dos valores afirmados na obra são de natureza e origem sentimental: bondade, alegria, coragem etc.:

“- 'Não sabe que quem é mesmo inteirado valente, no coração, esse também não pode deixar de ser bom?!" (fala de Diadorim - GSV, 143)

"O vau do mundo é a alegria!" (GSV, 288)

$$
\text { disse." 'Vau do mundo é a coragem ...' - eu }
$$

"Mas eu hoje em dia acho que Deus é alegria e coragem - que t̂le é bondade adiante, quero dizer." (GSV, 296)

Entretanto, na medida em que tais valores têm de ser vividos ("Deus é bondade adiante"), os mesmos são instaurados pelo homem na ação - e não transcendentes ou abstratos. Não obstante, é preciso ter-se em conta que tais valores, em que pese sua incidência e afirmação ao longo de toda a obra rosiana, expressam, no fundo, um modo particular de ser (sentimental, emocional etc.), e que embora postos e elevados à dignidade de valores morais, se se pensa a moral na sua relação com a prática de uma ação, dificilmente poderiam caracterizar uma ética. Impõe-se aqui, portanto, o problema dos tipos: não se pode definir como virtudes a alegria de um extrovertido ou a reserva do introvertido; da mesma forma, não se pode falar de "valor" em relação ao sentimento enquanto função superior do tipo-sentimento, assim como tampouco o é, moralmente, a superior "inteligência" do tipo-pensamento. Vista da perspectiva contrária, é a mesma situação pela qual, jurídica e moralmente, o louco ou débil mental não são considerados responsáveis pelo crime que cometem, ou ainda, da perspectiva religiosa, seu crime não é considerado "falta" ou "pecado". Só 
há virtude ou não-virtude ali onde se empenham (ou deixam de se empenhar) a vontade, a consciência e a liberdade individuais. Contra o comportamentismo, ainda é possível afirmar que o meio inclina, mas não obriga .

Neste sentido, a nosso ver, aquilo que Krolow chama o engajamento do coração ou do sentimento na obra rosiana, é precisamente aquilo que esta tem de mais pessoal: seja no sentido de uma auto-biografia sincera, seja - eventualmente - no sentido de uma compensação do exatamente oposto. "O artista é um fingidor..." - já o sabia Fernando Pessoa. Não estamos afirmando tal hipótese, mas apenas mostrando a necessidade de se tê-la em conta, em decorrência mesmo do fato de estarmos diante de uma obra que, se nos apresenta um tipo, ao mesmo tempo é obra de um artista.

Se, contrariamente, por valores genuinamente morais entendermos aqueles que dizem respeito à ação e suas conseqüências, aqui, sim, poder-se-á falar de uma ética rosiana esta porém de tipo muito mais voluntarista que sentimental. De início, refaçamos a "teoria dos valores" do narrador:

"Também, o que é que vale e o que é que não vale? Tudo." (GSV, 138)

A extensão absoluta do conceito ("Tudo") é não obstante mais circunscrita pelo próprio narrador, ao dizer que

\section{"O que vale são outras coisas." (GSV, 95, gri- fos nossos)}

Por sua vez, esta circunscrição do axiológico é logo novamente mais precisada - embora ampliada na ambigüidade de sua formulação:

"Mas, para mim, o que vale é o que está por baixo ou por cima - o que parece longe e está perto, ou o que está perto e parece longe." (GSV, 217 , grifos nossos)

Fazendo intervir o simbolismo da orientação espacial ("em pé" = vertical = consciente) mais um pouco se precisa esta "ambigüidade" quando o narrador declara que

"Só o que a gente pode pensar em pé - isso é que vale." (GSV, 276, grifos nossos) .

Se parecemos nos aproximar de uma ética do tipo racio- 
nalista e inoperante ("Só o que... pensar em pé - é que vale"), por outro lado a ação e a proversividade se impõem:

“Não sabia, hoje será que sei, a regra de nenhum meio-têrmo. Sem ação, eu podia gastar ali minha vida inteira, debulhando." (GSV, 83, grifos nossos)

"Tudo tinha me torcido para um rumo só, minha coragem regulada sòmente para diante, sòmente para diante." (GSV, 203, grifos nossos)

Entretanto, levando-se em conta o contexto ou experiência específicos a que se refere o narrador - a subjetividade em processo do seu mito pessoal em realização, travessia do "sertão"-inconsciente para a "cidade" da consciência-centro atingido - esta "ação", ao mesmo tempo que assume nova dimensão moral — condição da autonomia - retorna também ao seu sentido primeiro, mitológico e psicológico.

\section{DA HETERONOMIA A AUTONOMIA: SENTIDO E VALOR DA TRAVESSIA}

"Afirmo ao senhor, do que vivi: o mais difícil não é um ser bom e proceder honesto; dificultoso, mesmo, é um saber definido o que quer, e ter o poder de ir até no rabo da palavra." (GSV, 166, grifos nossos)

Ora, "ser bom" e "proceder honesto" apresenta, em relação à consciência individual, um duplo aspecto em que os têrmos finalmente se invertem: em primeiro lugar, na medida em que têm sua origem na cultura, representam para $a$ consciência individual, tanto o coletivo como o exterior: a heteronomia, pois; em segundo lugar, na medida mesma em que coletivos e exteriores, para a consciência que recebe tais valores como imposição externa (e não conquista interior), tais valores resultam, finalmente e à maneira do superego freudiano, inconscientes. O que é "dificultoso", pois, é a passagem da heteronomia coletivo-multiplicidade-inconsciente para a autonomia unidade-consciência. Não esquecer o

"conselho que Zé Bebelo, na Nhanva, um dia me tinha dado. Que era: que a gente carece de fingir às vezes que raiva tem, mas raiva mesma nunca não se deve de tolerar de ter. Porque, quando se curte raiva de alguém é a mesma coisa 
que se autorizar que essa própria pessoa passe durante o tempo governando a idéia e o sentir da gente; o que isso era falta de soberania, e farta bobice, e fato é." (GSV, 225, grifos nossos)

Através do universo de partes mei in aliis personalizadas por via de projeção, continuamente re-verificamos que o ético, para o narrador, está mais estreitamente vinculado ao psicológico do que fariam parecer suas falas tomadas isoladamente. Assim é que melhor se comprende quando o narrador diz que "Eu queria minha vida própria, por meu querer governada" (GSV, 335, grifos nossos), ou quando, se valendo das imagens extremas para o centro (ou eu profundo, ou si mesmo) e para a sombra (o reprimido, ou negativo), já Chefe - mas não narrador ainda, "pensa":

"- 'Não sou do demo e não sou de Deus!' pensei bruto, que nem se exclamasse." (GSV, 465, grifos nossos)

Afinal, o "govêrno" que definirá a autonomia moral, será (ou não) exercido em relação a um "estado" chamado "sertão":

"O sertão não tem janelas nem portas. E a regra é assim: ou o senhor bendito governa o sertão, ou o sertão maldito vos governa..." (GSV, 466, grifos nossos)

Desta forma, as relações de ordem moral que o narrador estabelece entre os domínios do sentimento e da vontade trazem-nos de volta às constatações anteriormente apontadas: o sentimento é um dado, fato da subjetividade que decorre do tipo psicológico; prima materia, deverá ser elaborado pela vontade para, qualitativamente transformado, assim ascender à eminência de "valor". Neste sentido e para tal objetivo - a vontade (seu uso e exercício a partir da liberdade) é "anterior" e "superior" ao sentimento em questão. Esse esquema de relações, embora constante em todo o conjunto da obra rosiana, encontra sua mais clara formulação na Secção IV do quarto prefácio de Tutaméia ("Sobre a escôva e a dúvida"). Introduzindo um equivalente do compadre meu Quelemém, ao qual (não por acaso) chama "o meu guru Weridião" (18) assim se encontra condensada a concepção moral do homem rosiano:

(18) ROSA, João Guimarães - Tutaméia - Terceiras Estórias, 3. ${ }^{\text {a }}$ ed., Rio de Janeiro, José Olympio, 1969, p. 153. 
"Suspeito nem sequer minhas vontades profundas. Sob a palavra de Weridião, somos os humanos sêres incompletos, por não dominados ainda à vontade os sentimentos e pensamentos. E precisaria, cada um, para simultaneidade no sentir e pensar, de vários cérebros e corações. Quem sabe, temos? Sem amor, eu é que sou um Sísifo sem gravidade." (19)

Ainda aqui coerente com Jung - ao diferenciar "os sentimentos" do amor como uma forma do sentimento - ainda aqui encontramos "os humanos sêres incompletos" definidos a partir do herói (Sísifo). Para efeito de verificação da hipótese de um voluntarismo moral que, se não sobrepuja o "engajamento do sentimento", teria como este o mesmo significado ético final, seja-nos permitido adotar, neste domínio, as convenções gráfico-espaciais da formalização matemática, e assim "deduzir" em "fórmula" aquela que se revela a forma da ética rosiana:

$\frac{\text { VONTADE }}{\text { sentimento }- \text { pensamento }}+$ AMOR

(Sentimento e pensamento sub vontade, mais amor)

Assim é que, escapando continuamente de todo abstrato e puramente intelectual, a ética do narrador assume a concretude espêssa e humana do psicólogico vivido como um

"trabalho de segurar a alma e endurecer as mãos." (GSV, 180, grifos nossos)

Nem absoluta liberdade ou livre arbítrio absoluto, nem destino estrito, fatalismo ou determinismo, se não se pode falar de uma autonomia da moral no pensamento rosiano, necessário é reconhecer-lhe a precisa formulação de uma moral da autonomia. Profundamente humana, porque fundada no que de mais profundo tem o homem; profundamente naturalista, porque fundada no imediato do psicológico; profundamente realista, porque expressa pelo irreal do mito; profundamente concreta, porque tarefa de todos nós. Qualquer análise desta ética, sem qualquer juízo de valor, seria um non-sense. Mais que qualquer síntese, porém,

(19) Idem, p. 154. Grifos nossos. 
"Estou dando batalha." (GSV, 296)

E mais sintético ainda, o narrador tudo diz ao dizê-lo em uma única palavra:

“Cumpro." (GSV, 571) 